
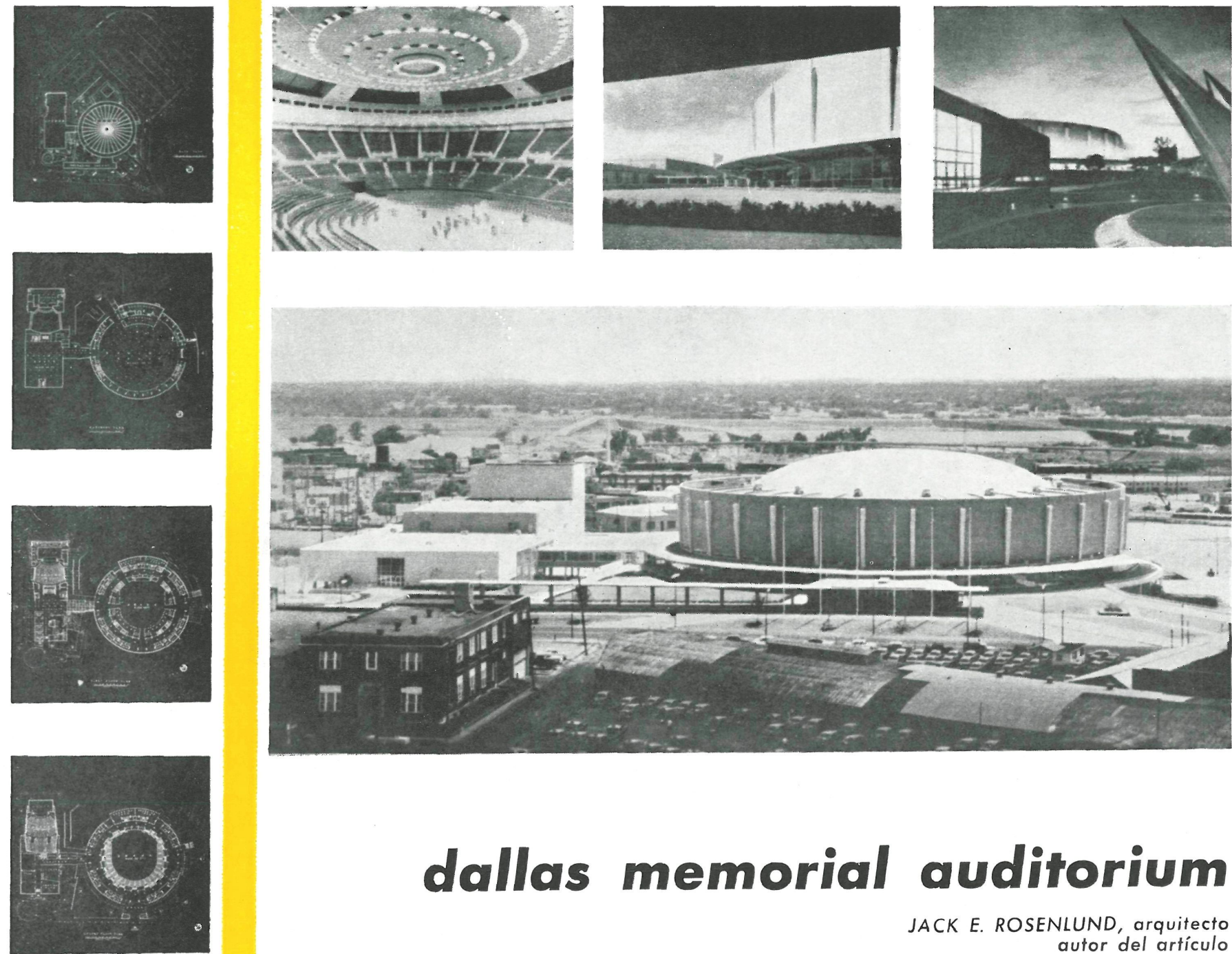

\title{
dallas memorial auditorium
}
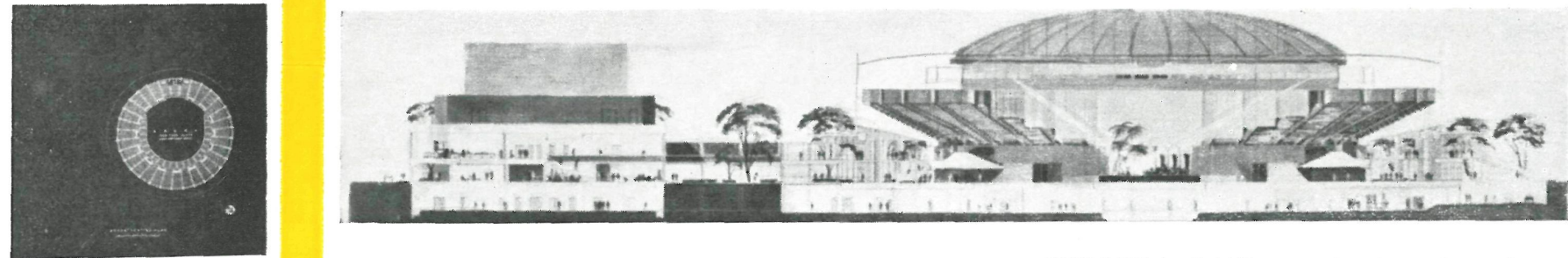

proyecto: GEORGE L. DAHL, arquitectos e ingenieros estructura: AMMANN y WHITNEY, ingenieros consultores

$152-38$

La ciudad de Dallas precisaba de un edificio monumental de uso vario-para congresos, representaciones de ópera, espectáculos circenses, competiciones deportivas, exposiciones, conciertos, etc._, con amplio espacio para estacionamiento de vehículos y buenos transportes.

El complejo constructivo consta de dos edificios fundamentales, auditorio y liceo, enlazados por un elemento bajo de paso y comunicación. Ambos cuerpos tienen acceso directo, desde la calle, a sus tres niveles. 


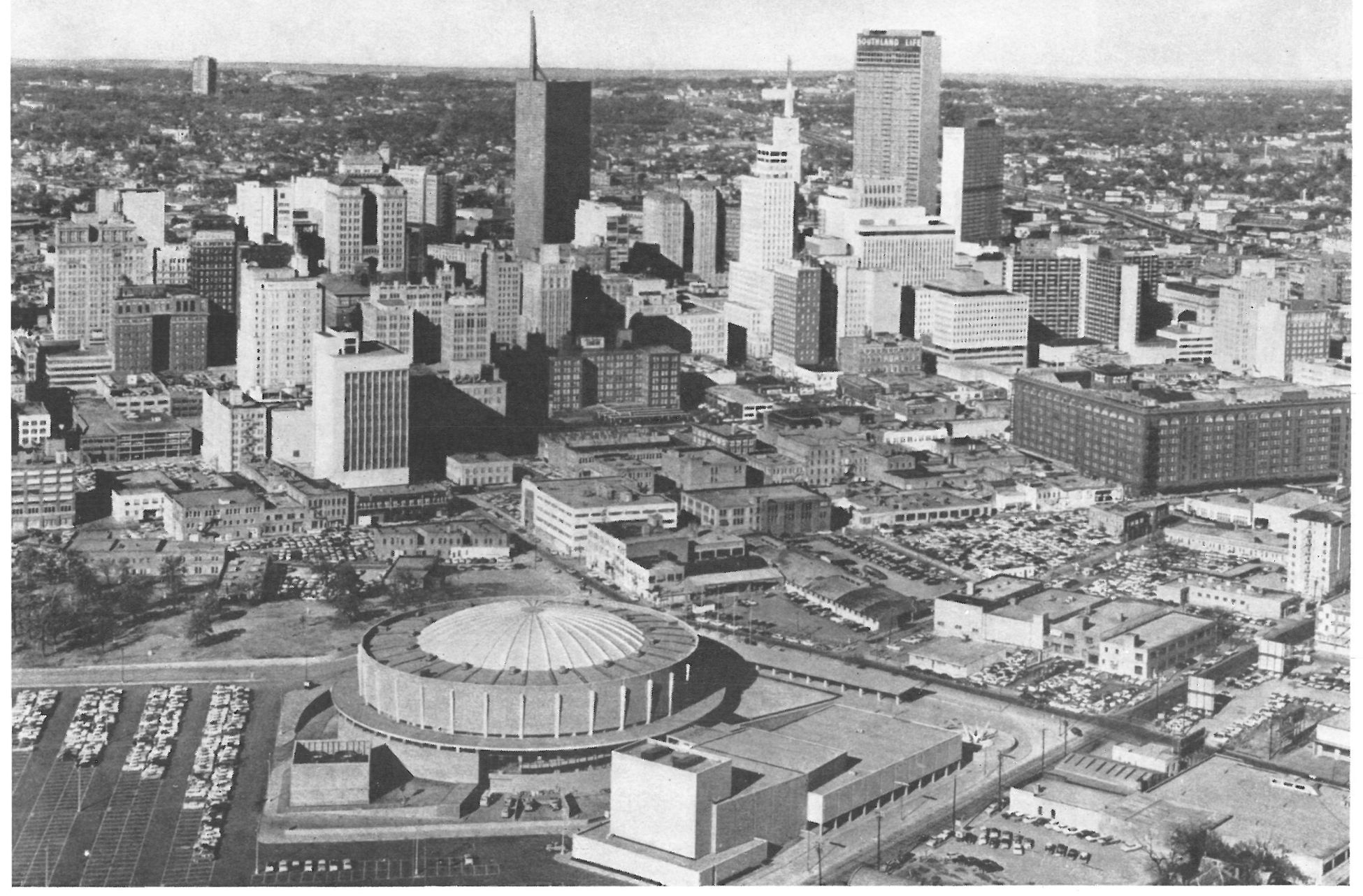

El liceo es un edificio prismático con planta rectangular, de $56,5 \times 30,5 \mathrm{~m}$, y que contrasta formalmente con la fisonomía circular del auditorio. La planta en círculo de este último fué adoptada, después de varios ensayos, porque permite un mayor aforo para perímetro menor. Las mismas consideraciones de tipo funcional, económico y de aprovechamiento, impulsaron a la adopción de un tipo de cubierta curva, con todo lo cual se ha conseguido un volumen reducido de capacidad máxima, partiendo de las premisas y datos fijados.

Un edificio de este tipo presenta serios y complicados problemas de cálculo, que conducen, muchas veces, como en este caso, a soluciones nuevas. La cubierta, de doble curvatura, se ha dividido en 16 sectores, con estructura porticada radial, cuyos elementos verticales se acusan limpiamente en fachada en sus $21 \mathrm{~m}$ de altura. 


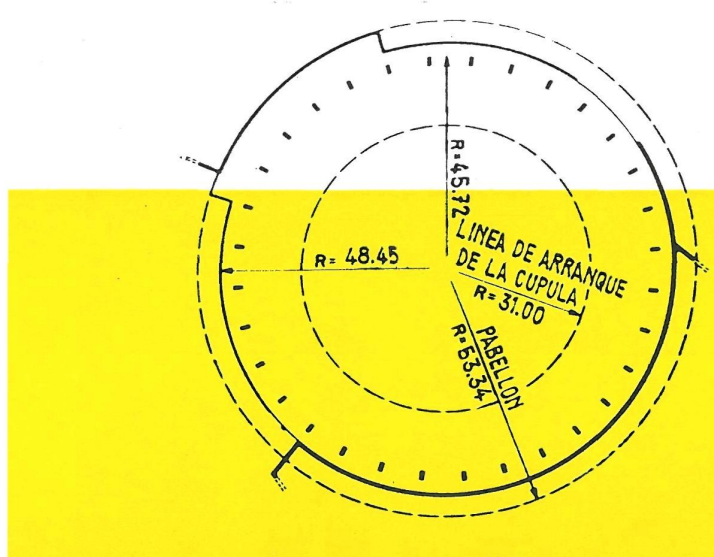

(2)

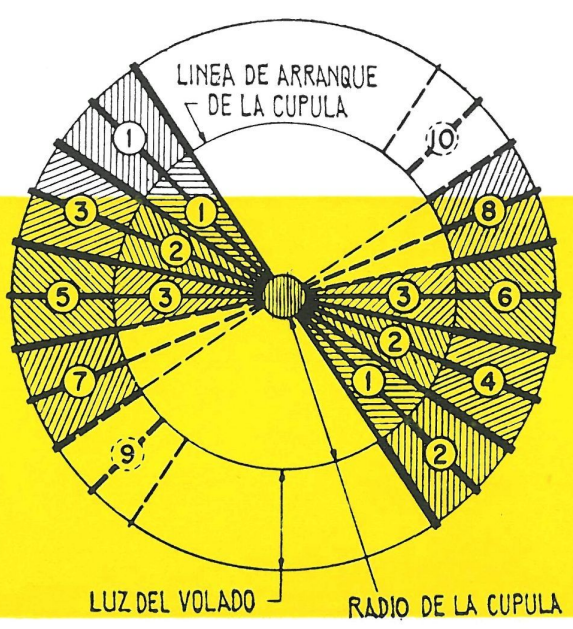

diagrama estructural

planta

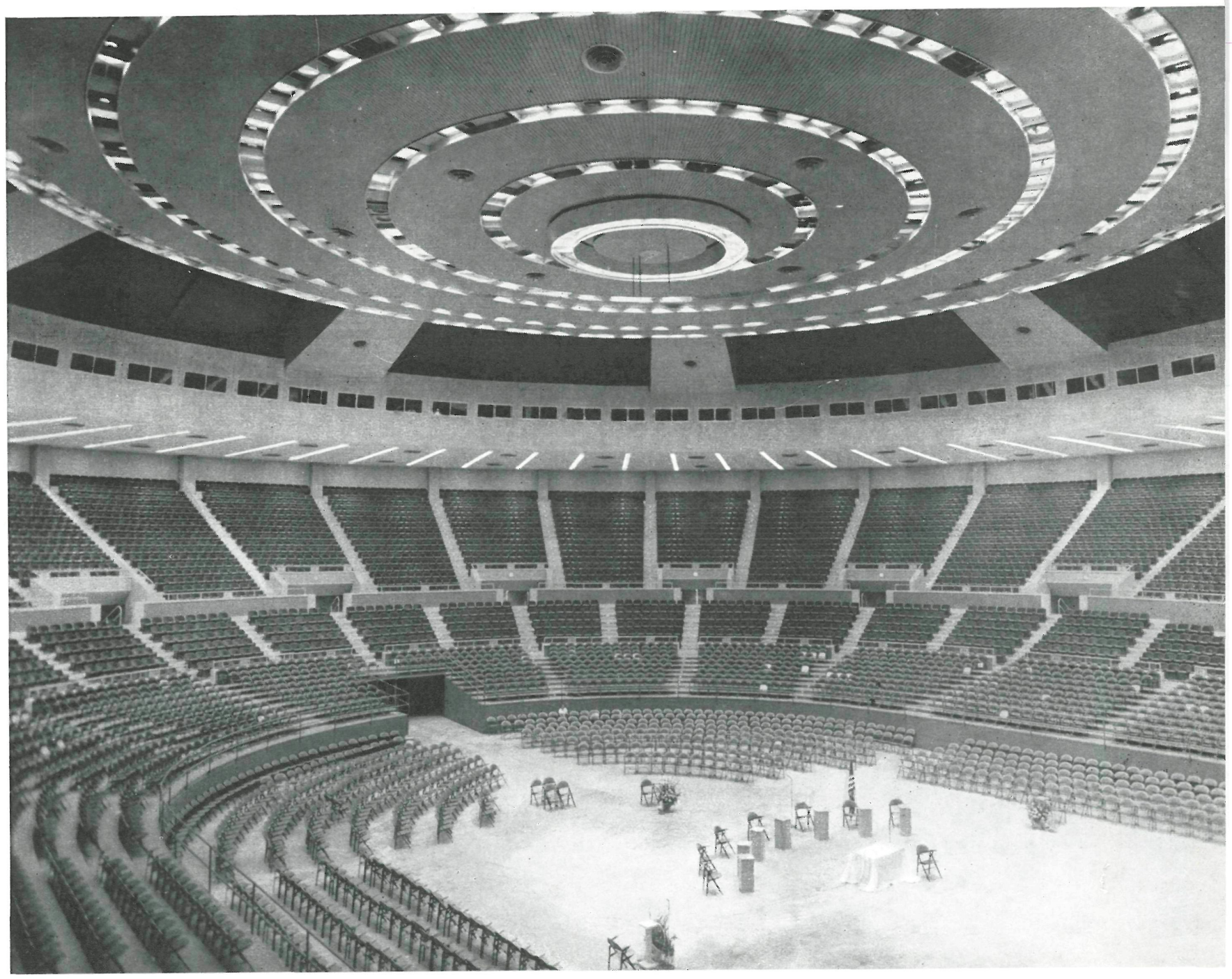




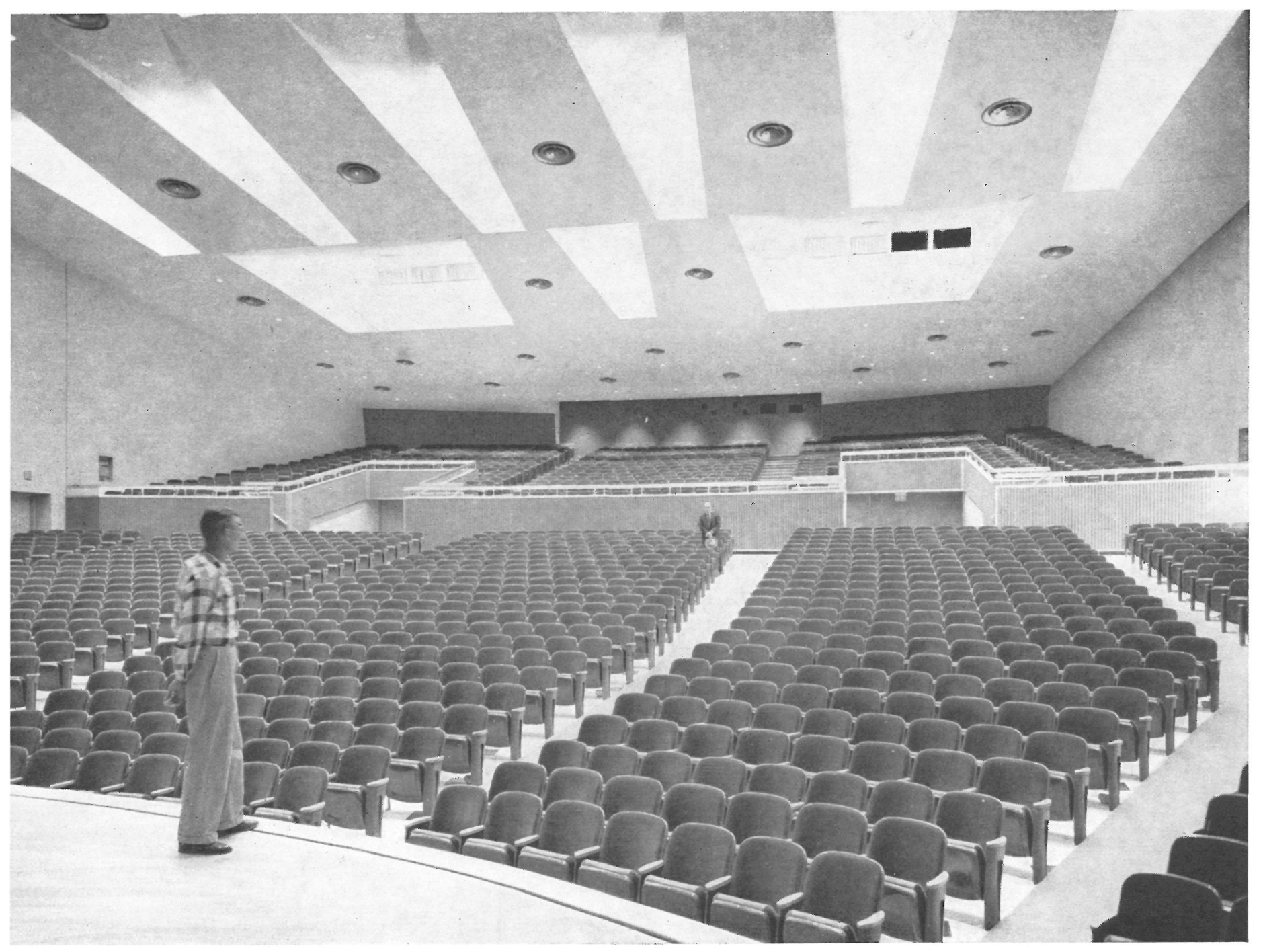

En general se ha procurado que todos los materiales que intervienen en la construcción queden sinceramente destacados, sin falseamiento alguno, con lo que se ha conseguido una apariencia espontánea, grata y económica. Los cerramientos de ladrillo y la estructura de hormigón armado campean así con libre desnudez, mostrando claramente la función que desempeñan en la obra.

Tanto el sistema de acondicionamiento acústico como las instalaciones de iluminación cambiable_adaptándose a cualquier espectáculo o representación, radio, televisión, etc.se han cuidado al máximo, cual corresponde a una sala en la que todo será función de sensaciones acústicas y visuales.

El edificio circular tiene un diámetro libre de $91,5 \mathrm{~m}$, cubriendo la cúpula central un círculo de $62 \mathrm{~m}$ de diámetro. 